\title{
Ups and Downs: Emotional Dynamics in Negotiations and Their Effects on (In)Equity
}

\author{
Michele Griessmair $^{1,2}$ (D)
}

Published online: 4 September 2017

(C) The Author(s) 2017. This article is an open access publication

\begin{abstract}
Organizational scholars now acknowledge the relevance of emotions in virtually every aspect of organizational life, including negotiations and conflict resolution. Integrating negotiation phase model theory with social functional models of emotion, we test hypotheses about the development of emotions in negotiations and their effects on the degree of economic (in)equity of the counterpart's subsequent offer during the actual negotiation process. By comparing stalemate dyads with efficient settlement dyads, the study identifies emotional dynamics that characterize successful as opposed to unsuccessful negotiations. Results show that observed differences are primarily the result of impasse dyads spiraling into a negative emotional climate rather than efficient settlement dyads having overall higher levels of positive emotions or increasing them throughout the negotiation process. As predicted by social functional models, the study further confirms that emotions are not only a reaction to the economic (un)fairness of a proposed offer, but their display also influences the payoff (in)equity of the counterpart's subsequent offer. Whether a specific emotional expression increases or decreases the economic fairness of the counterpart's subsequent offer, however, differs across negotiation phases and between dyads that reached an agreement or not. Furthermore, the results show distinct differences between emotions that address individual goal realization in negotiations and emotions that focus on the
\end{abstract}

Michele Griessmair: Supported by an Erwin Schrödinger Fellowship from the Austrian Science Fund (J 3866-G27).

$凶$ Michele Griessmair

Michele.Griessmair@univie.ac.at

1 Sir Zelman Cowen Centre, Victoria University, 295 Queen Street, Melbourne, VIC 3000, Australia

2 Faculty of Business, Economics and Statistics, University of Vienna, Oskar-Morgenstern-Platz 1, 1090 Vienna, Austria 
relational, interpersonal aspect of negotiations, both with regard to their development as well as their function. Taken together, the results shed light on the mechanisms leading to the emergence of conflict spirals.

Keywords Negotiation $\cdot$ Emotions $\cdot$ Equity $\cdot$ Negotiation phase model

\section{Introduction}

Since the rediscovery of affect in the mid-1980s and the 1990s (Brief and Weiss 2002), a plethora of research on mood and emotion in organizational settings has emerged. Scholars now acknowledge that "affect permeates virtually every aspect of organizational life, even those areas that have been traditionally thought of as the exclusive province of cognitive behavior" (Barsade and Gibson 2007: 51). Extensive evidence shows that affect influences decision making, creativity, leadership, group processes and outcomes, cooperation and helping behavior, job satisfaction, turnover, absenteeism, and motivation as well as a variety of performance indicators (Barsade and Gibson 2007; Brief and Weiss 2002).

Another area in which emotions have gained considerable attention in recent years is negotiation and conflict resolution research (Druckman and Olekalns 2008; Martinovsky 2015b). Negotiations are not only an integral and ubiquitous part of organizational life (Olekalns and Weingart 2003) with significant economic consequences (Brett et al. 1998; Olekalns and Weingart 2003) but they are also inherently emotional (Morris and Keltner 2000). Brief and Weiss (2002: 295) even view negotiations as "a natural setting for the study of affect." Early work considered emotions primarily as having a detrimental effect in negotiations, impeding performance and successful coordination (Druckman and Olekalns 2008, 2015). More recent research, however, acknowledges the complex nature of affect, showing that both positive as well as negative emotions have important functions in negotiations (Van Kleef et al. 2010). This research has established strong empirical evidence that emotions impact the negotiator's own behavior and decisions, the counterpart's reaction and, in consequence, the outcome of the negotiation-sometimes beneficially and sometimes in a harmful manner (for reviews, see, Druckman and Olekalns 2008, 2015; Griessmair et al. 2015).

The majority of these studies, however, have treated emotions as a static phenomenon rather than considering the process-like, interactive nature of emotions and their development during the course of the interaction (Fischer and Van Kleef 2010). Negotiations are dynamic processes with alternating cooperative and competitive periods (Adair and Brett 2005; Bednar and Curington 1983; Holmes 1992; Lytle et al. 1999). Similarly, a number of scholars emphasize that emotions are not stationary but wax and wane over time (Fischer and Van Kleef 2010; Gibson and Fichman 2006; Griessmair and Koeszegi 2009). Furthermore, emotions may have different functions and varying impact at different phases of the negotiation (Martinovsky and Mao 2009; Martinovsky et al. 2007; Morris and Keltner 2000).

The purpose of this study is to integrate phase model theory of negotiations with social functional models of emotions in order to investigate how emotions evolve during the course of the negotiation and how the display of specific emotions affects the 
degree of payoff (in)equity of the counterpart's subsequent offer, that is, the extent to which the negotiators claim more value for themselves compared to their counterpart. Several studies have shown that negotiators that reached an agreement exhibit a higher level of positive emotions compared to negotiators that ended in a stalemate (e.g., Anderson and Thompson 2004; O'Conner and Arnold 2001) and that negotiators' emotional expressions influence their counterparts' behavior (Sinaceur and Tiedens 2006; Van Kleef et al. 2004). Employing discourse analysis, Martinovsky (Martinovsky 2015a; Martinovsky and Mao 2009) exemplifies how emotions contribute to the changes of goals and strategies during the negotiation. We contribute to this literature by investigating the actual negotiation process and the emotional dynamics differentiating stalemate dyads from dyads reaching an efficient agreement. Based on phase model and emotion theories, we propose that emotional differences observed in previous studies primarily result from impasse negotiators spiraling into a negative emotional climate rather than negotiators reaching an efficient outcome increasing their level of positive emotions throughout the negotiation.

Furthermore, we propose that the effect that emotional expressions have on the counterpart's behavior differs across negotiation phases. Thereby, we also take a new look on the relationship between emotions and (in)equity. Previous theory and research has mainly focused on the role of emotions in the emergence of fairness evaluations (Cropanzano et al. 2011) or emotional reactions to (un)fair events (Hegtvedt and Killian 1999). We complement this literature by showing that emotions are not only a reaction to the subjective experience of unfairness but that their display also influences the degree of economic (in)equity of the counterpart's subsequent offer. Notably, whether a specific emotional expression increases or decreases the payoff-equity of the counterpart's subsequent offer differs across negotiation phases and between dyads that ultimately reached an agreement or not. Finally, although not a specific aim of the study, the results also shed light on the mechanisms leading to the emergence of conflict spirals.

The reminder of the article is structured as follows. First, after a general outline and definition of relevant concepts, we describe social functional models of emotions and the related emotional dimensions employed in the present study (Sect. 2.1). Second, we derive hypotheses about the emotional development across the three negotiation phases - initiation, problem solving, and endgame - and the effects of emotional expressions on the payoff (in)equity of the counterpart's subsequent offer in each phase (Sect. 2.2). Third, we describe the research design, data collection, and the elicitation of payoffs and emotions (Sect. 3). Fourth, we illustrate the findings and discuss their implications (Sects. 4, 5).

\section{Theory and Hypotheses}

A negotiation can be defined as a process through which individuals that are mutually dependent on each other in attaining their goals disagree or are in conflict and attempt to reach a solution (Lewicki et al. 1999). Emotions are most likely to emerge in social relationships of interdependence and power and reflect the rate of progress individuals make towards achieving their goals (Carver and Scheier 1990; Lazarus 1991). This 
makes negotiation a natural setting for the study of affect (Brief and Weiss 2002). In contrast to mood, emotions are not only more intense and short-lived but are also elicited by and directed to a specific event in one's environment (Lazarus 1991). As a consequence, emotions have more distinct antecedence conditions and are also more likely to influence beliefs and behavior (Lazarus 1991). For the present analysis we consider emotions in mixed-motive, deal-making negotiations. In mixed-motive negotiations individuals are mutually interdependent from each other in achieving their goals and have incentives to both cooperate as well as compete. Thus, the setting provides a motivation for both parties to experience and display positive and negative emotions with regard to goal attainment as well as relationship.

We complement the social-psychological concept of emotions with economic criteria to characterize the negotiation in terms of (in)equity and outcome. The degree of economic (in)equity of the exchanged offers is captured by the difference in payoffs between the two negotiators, referred to as contract balance (Foroughi et al. 1995). It reflects the degree to which an offer is disproportionately more advantageous to one side and the degree to which negotiators claim value for themselves compared to what they offer to the counterpart.

With respect to the negotiation outcome, we consider negotiation dyads that achieved a Pareto optimal settlement in terms of payoffs and compare them to dyads who decided that an agreement was not possible. An outcome is Pareto efficient if there are no alternatives available that leave one party better off while not making the counterpart worse off (Tripp and Sondak 1992). By considering Pareto optimal outcomes in our theorizing and empirical study, we also address the quality of the outcome. In negotiations, it is not only important that the involved parties reach a settlement but also whether they are successful in creating value during the process rather than agreeing to a suboptimal solution. Furthermore, by comparing dyads that achieved an efficient agreement with dyads that 'agreed to disagree', we consider that both, settlement and impasse dyads, aspired to achieve a good outcome in lieu of giving in unilaterally for the sake of reaching an agreement. However, whereas the former were successful in reaching a mutually satisfactory outcome with high joint gain, the latter failed to do so. Finally, by examining efficient settlement in comparison to impasse dyads we complement previous studies investigating the effect of emotions on the counterpart's offer. These studies have shown that displays of anger as opposed to happiness result in larger concessions by the counterpart (Van Kleef et al. 2004), however, they did not address the outcome quality ultimately resulting from this behavior.

\subsection{Social Functions of Emotions in Negotiations}

The so-called social functional approach focuses on relational functions of emotions and on the effects that expressed emotions have on others rather than the individual experiencing them (Fischer and Van Kleef 2010). Accordingly, emotions are not only simple readouts of internal experiences but communicative acts that shape relationships and serve specific purposes in social interactions (Morris and Keltner 2000). Reviews of the social functional and alternative approaches of emotion in negotia- 
tions are given in, for instance, Morris and Keltner (2000), Van Kleef et al. (2010), Druckman and Olekalns (2015), Martinovsky (2015a), and Griessmair et al. (2015).

Following the social functional approach, we consider two affective dimensions characterizing emotions and their functions in negotiations: pleasure-displeasure and other- versus self-oriented emotions. According to the dimensional approach, emotions can be organized along a few fundamental dimensions (Mauss and Robinson 2009) representing attributes that capture the shared variance among discrete emotional states (Feldman 1995). Thus, rather than specific single emotions, general properties characterizing the multitude of possible emotional states are considered. In literature, several such dimensions have been proposed (for reviews, see, Mauss and Robinson 2009; Russell and Feldman Barrett 1999). In the context of negotiations, however, the dimensions pleasure versus displeasure and other- versus self-oriented emotions appear to be the most appropriate. Negotiators are mutually interdependent in attaining their goals (Lewicki et al. 1999), thus they must balance the pursuit of their desired outcomes with relational concerns in a potentially conflicting situation. Whereas pleasure versus displeasure addresses individual goal realization in negotiations, other- versus self-oriented emotions comprise the relational, interpersonal aspect of negotiations. The two emotional dimensions are grounded in theory; however, their choice was also driven by the inductive component in the empirical study (cf., Adair and Brett 2005). As will be elaborated more in detail in the method section, we decided to include an inductive element in the emotion elicitation process to guarantee the appropriateness of the chosen emotions in the context of negotiations.

\subsubsection{Pleasure Versus Displeasure}

Pleasure versus displeasure represents a basic quality of emotional evaluation and describes the subjective feeling of (un)pleasantness associated with an emotional experience (Feldman 1995). In the context of negotiation, the emergence of pleasure or displeasure is primarily related to the progress individuals make towards obtaining their goals (Fischer and Van Kleef 2010; Kumar 1997; Van Kleef et al. 2010) as posited by appraisal theories of emotion (Lazarus 1991). Accordingly, individuals perform a cognitive evaluation of an event, which in turn gives rise to the emotional experience (Carver and Scheier 1990). Extending this view to a social functional perspective, the display of the experienced pleasure or displeasure constitutes a communicative act, potentially influencing the further course of the negotiation (Morris and Keltner 2000). For instance, when the counterpart's actions are counterproductive for the realization of a negotiator's objectives, she or he is likely to react with displeasure (e.g., anger or frustration) (Van Kleef et al. 2010). This, in turn, signals to the counterpart that behavioral adjustment is required in order to obtain a mutually satisfactory outcome and serves as a potential deterrent to exhibiting that behavior in the future (Barry et al. 2004; Morris and Keltner 2000). When, on the other hand, negotiators make reasonable progress towards achieving their objectives it is likely that pleasure (e.g., happiness or joy) will emerge (Van Kleef et al. 2010). The display of these emotions indicates that the negotiators are on the right track and provides an incentive to exhibit similar behavior in the future (Barry et al. 2004; Morris and Keltner 2000). 


\subsubsection{Other-Versus Self-Oriented Emotions}

Other- versus self-oriented emotions focus on the social, interpersonal meaning of emotions, including tendencies toward approach or avoidance, the degree of affiliativeness, potency, aggression, submission versus dominance, and solidarity versus conflict (Markus and Kitayama 1991; Osgood 1969; Russell and Mehrabian 1977; Watson et al. 1999; White 2000). These characteristics can be summarized under selfversus other-orientation. Whereas self-oriented emotions such as anger, frustration, or pride exhibit low levels of affiliativeness and involve conflict and dominance, otheroriented emotions such as regret, shame, guilt or feelings of familiarity and respect comprise affiliativeness, submission, and solidarity. Emotions related to this dimension are typically associated with failure or success in nurturing a relationship and have another person rather than individual goals as the primary referent (Kumar 1997; Markus and Kitayama 1991). The expression of other- and self-oriented emotions during an interaction provides information about how a negotiator perceives the relationship, promotes or disrupts interdependence, and signals whether a transgression in the relationship is perceived as such and one is inclined to make amends (Markus and Kitayama 1991; Van Kleef et al. 2010).

\subsection{Emotional Development and Effects on (In)Equity}

In negotiation research, extensive evidence shows that negotiators' behavior is not invariant over time but that competitive and cooperative periods alternate (Adair and Brett 2005; Bednar and Curington 1983; Holmes 1992; Lytle et al. 1999). This interplay between cooperation and competition over time is investigated in phase model theory. Phase model theory posits that negotiations advance through an evolutionary process. The overall interaction can be subdivided into larger units, the phases, each with specific characteristics shaping the progression of the negotiation (Holmes 1992). In addition to the general development of negotiation processes, empirical studies grounded in phase model theory show that the timing with which specific strategies and tactics are employed differs between successful and unsuccessful negotiators (Adair and Brett 2005; Olekalns et al. 2003, 1996). Considering that emotions are a dynamic phenomenon, it is reasonable to assume that a similar pattern is observable. Although individual phase models vary considerably, Holmes (1992) identified three general phases with common characteristics across models. These phases vary according to their competitive and cooperative climate. Following social functional models of emotions, most prominently the Emotions as Social Information (EASI) model (Van Kleef et al. 2010), we expect that emotions have different effects on the (in)equity of the subsequent offer in the different phases.

\subsubsection{Initiation}

Theoretical models as well empirical studies document that negotiations are more likely to begin with a distributive, contentious phase (Adair and Brett 2005; Bednar and Curington 1983; Holmes 1992; Lytle et al. 1999). As pointed out by Adair and Brett 
(2005: 35), at this early stage the parties have little information about the counterpart's needs and interests but they usually "know what they want and assume the other party wants the opposite (the fixed-pie bias)". Accordingly, rather than using rational argumentation and exchanging information to address common interests, the negotiators focus on affective persuasion, make ambit claims, and communicate their perceived rights and sources of power (Adair and Brett 2005; Lytle et al. 1999; Olekalns et al. 2003). The offers made in the first phase are used by the negotiators to stake their claims and act as an anchor from which to make subsequent concessions (Adair and Brett 2005). Thus, it is likely that the initial competitive posturing will be reflected in rather one-sided, unbalanced offers in the first phase.

The competitive climate of the first phase also affects the counterpart's reaction to emotional displays. Van Kleef et al. (2010) conclude that competitive settings such as the initiation phase are characterized by more selfish motivations and strategic behaviors. In such situations, they argue, negotiators use their counterpart's emotional display to make strategic inferences and primarily focus on the strategic implications of the expressed affect. Displaying pleasure in competitive settings indicates that the counterpart's limits are not yet reached and may be interpreted as sign of weakness and that the other is gaining at one's expense (Van Kleef et al. 2004, 2010). Accordingly, positive emotions induce the counterpart to be more competitive, make higher demands, and claim value (Van Kleef et al. 2010). Negative emotions, on the other hand, are not only detrimental but have important informational functions and act as negative reinforcers (Barry et al. 2004; Morris and Keltner 2000). They signal that a negotiator's limits have been reached, that behavioral adjustment is required in order to obtain a mutually satisfactory outcome, and serve as potential deterrent to exhibiting that behavior in the future (Barry et al. 2004; Morris and Keltner 2000; Van Kleef et al. 2004). To prevent negative consequences, the counterpart is likely to react with more cooperative behavior (Van Kleef et al. 2010). Thus, in line with the EASI model, we propose that displaying higher levels of pleasure as compared to displeasure in the competitive initiation phase will induce the counterpart to make economically more one-sided offers.

Hypothesis 1a A negotiator's display of higher levels of pleasure in phase one decreases the payoff-equity of the counterpart's subsequent offer.

Effective negotiation, however, necessitates balancing competitive and cooperative strategies and building an appropriate climate (Lytle et al. 1999). Accordingly, empirical studies show that the first phase is not only characterized by the aforementioned competitive behaviors, but that negotiators also engage in relationship building and establishing goodwill (Adair and Brett 2005). Thus, the initiation phase has a dual focus. On one hand, negotiators engage in competitive posturing to stake their claims. At the same time negotiators have to establish a positive working climate and express goodwill in order to find a common ground for future interaction. Morris and Keltner (2000) suggest that this "initiation problem" is addressed by conveying affiliative intent in the opening moves. Thus, we expect that displaying higher rather than lower levels of other- compared to self-oriented emotions will signal willingness to move towards the negotiation partner and elicit an offer with higher payoff-equity by the counterpart. 
Hypothesis 1b A negotiator's display of higher levels of other-oriented emotions in phase one increases the payoff-equity of the counterpart's subsequent offer.

\subsubsection{Problem Solving}

The central block of the negotiation process has been labeled in the literature as reconnoitering the range, narrowing the differences, problem identification, and problem solving (Adair and Brett 2005; Gulliver 1979; Holmes 1992; Morris and Keltner 2000). After the relational posturing of the first phase, negotiators start to clarify the negotiation problem and to discuss the issues at hand (Adair and Brett 2005). This includes the exchange of information, building trust, discussing underlying interests, a mutual search for options, and exploring potential areas of agreement (Adair and Brett 2005; Morris and Keltner 2000). As shown by Lytle et al. (1999), the transition from the first to the next phase is also marked by a decrease of contentious tactics as well fewer discussions related to power and rights. Overall, negotiators shift from the competitive interaction observable in phase one to a more cooperative climate. In such a setting, the EASI model predicts that the expression of positive emotions triggers cooperation. In cooperative settings, in which negotiators are motivated to work together in order to achieve common goals, emotions have less strategic value. Emotions are not used to make strategic inferences, but they affect the social interaction via a process referred to as emotional contagion or affect infusion (Forgas 1998). Thus, positive emotions are likely to spread among the negotiators, resulting in cooperative behavior. Conversely, according to the EASI model negative emotions reduce cooperation in cooperative settings because they convey adverse signals and elicit similar emotions in the counterpart. Thus, we expect that signaling that the negotiation is on the right track and willingness to come closer to the counterpart by the expression of higher levels of pleasure and higher levels of other-oriented emotions will induce the counterpart to make offers that are more balanced.

Hypothesis 2a A negotiator's display of higher levels of pleasure in phase two increases the payoff-equity of the counterpart's subsequent offer.

Hypothesis 2b A negotiator's display of higher levels of other-oriented emotions in phase two increases the payoff-equity of the counterpart's subsequent offer.

After having set a high anchor with rather one-sided offers in the first phase, negotiators eventually have to concede and make offers that are more equitable to their counterparts. Negotiators start with ambit claims to establish a strong position in order to achieve an outcome closer to their aspiration level and subsequently make concessions moving towards the middle of the zone of possible agreements (Olekalns et al. 2003). Thus, we expect that both settlement and impasse negotiators make less onesided offers in the second phase. However, as pointed out by Vetschera and Filzmoser (2012), the foundation for agreements is already laid in the middle of the negotiation by reducing the inequity of offers, and settlement dyads are characterized by making more mutual concessions on crucial issues. Thus, we also expect that dyads that make offers with higher payoff-equity in the problem solving phase are more likely to reach an agreement. 
Hypothesis 2c In phase two, both impasse and efficient settlement dyads are characterized by offers with higher payoff-equity than in phase one.

Hypothesis 2d Dyads that make more equitable offers (in phase 2) are more likely to reach an agreement.

According to appraisal theories, individuals engage in a cognitive evaluation of an event including its personal significance, whether it is beneficial or detrimental for their personal goals, and causal ascriptions of responsibility (Carver and Scheier 1990). This, in turn, gives rise to the emotional response that consists of subjective experience, physiology, and behavior (cf., Mauss and Robinson 2009). Stalemate dyads in phase two are likely to sense that they are not making the progress they expected, both on a relational level as well as in terms of individual goal realization, resulting in a decline of positive emotions (Carver and Scheier 1990; Kumar 1997; Van Kleef et al. 2010), especially when the failure in reaching the set goals is attributed to the counterpart (Barclay et al. 2005). Furthermore, according to Andersson and Pearson's (1999) model, a fairness violation such as an offer with unbalanced payoffs may result in negative emotions and the desire to retaliate. As Andersson and Pearson (1999: 460) point out, the "most commonly employed means of releasing negative affect and restoring fairness in this situation is to reciprocate with further unfairness". This, in turn, increases the likelihood that the other party responds in kind resulting in a cycle of offers with unbalanced payoff and the expression of negative emotions (Brett et al. 1998; Friedman et al. 2004). In summary, negotiators who experience lack of progress towards their goals and engage in the aforementioned cycle are likely to experience and express negative emotions. Thus, we expect that dyads that have increased displeasure and self-oriented emotions in the problem solving phase are more likely to impasse.

Hypothesis 2e Dyads that express increased levels of displeasure from phase one to phase two are more likely to impasse.

Hypothesis $2 \mathrm{f}$ Dyads that express increased levels of self-oriented emotions from phase one to phase two are more likely to impasse.

Negotiations in which the parties reach an agreement, on the other hand, are characterized by a central block of integration that brings the parties closer to each other (Olekalns et al. 2003). Furthermore, they engage in the exchange of priority information on underlying interests, have established mutual trust, and are moving towards a joint solution (Adair and Brett 2005; Holmes 1992). Thus, appraisal theories suggest an increase in the experience and expression of positive emotions. This notion is also in line with previous research showing that negotiators reaching an agreement experience higher levels of positive affect than impasse negotiators (Anderson and Thompson 2004; O'Conner and Arnold 2001).

Yet, according to Gelfand et al. (2006), increasing positive affect as well as cooperative behavior is likely to result in a relational satisficing dynamic. They argue that negotiators engaging in a cyclical process of cooperation, accommodation, and positive affect build considerable relational capital. They are, however, not necessarily effective at achieving high individual or joint outcome because they avoid 
disagreement on task-related issues, prioritize relational over substantive issues, and risk ending the negotiation prematurely. Furthermore, effective bargaining in the central block of the negotiation requires a shift to more rational argumentation, appealing to facts and alternatives, and exchanging priority information rather than using the relational posturing and affective persuasion of the first phase (Adair and Brett 2005). Thus, it is likely that efficient settlement dyads do not increase pleasure and other-oriented emotions but maintain the emotional level established in the first phase.

In summary, we expect that emotional differences between efficient settlement and impasse dyads emerge in the central block of the negotiation, however, we hypothesize that they primarily result from impasse dyads decreasing the level of pleasure and otheroriented emotions rather than efficient settlement dyads increasing it (see hypotheses $H 2 e$ and $H 2 f$ ).

Hypothesis $2 \mathrm{~g}$ In phase two, efficient settlement dyads exhibit higher levels of pleasure than impasse dyads - the difference results from impasse dyads decreasing the level from phase one to phase two rather than efficient settlement dyads increasing it.

Hypothesis $2 \mathbf{h}$ In phase two, efficient settlement dyads exhibit higher levels of otheroriented emotions than impasse dyads - the difference results from impasse dyads decreasing the level from phase one to phase two rather than efficient settlement dyads increasing it.

\subsubsection{Endgame}

In the final phase, the endgame, negotiators become more competitive again. According to Bednar and Curington (1983), negotiations begin competitively as the parties identify differences and posture for position, shift to cooperation as they narrow differences and engage in problem solving, and end competitively as the parties contest for a final advantage. The negotiators have exhausted their rational arguments for claiming value and most of the information is on the table (Adair and Brett 2005). Thus, the focus is on exchanging proposals (Lytle et al. 1999). Rather than trying to persuade the counterpart, negotiators use a short format of communication, employ choice alternatives, and reject the other party's offers by making counter-offers (Adair and Brett 2005). Because the possibilities for creating value were reaped in the second phase, the parties now focus on committing the counterpart to agree to a given settlement and getting as much individual outcome as possible (Adair and Brett 2005). Thus, similar to phase one, we hypothesize the following based on the predictions of the EASI model for a competitive climate:

Hypothesis 3a A negotiator's display of higher levels of pleasure in phase three decreases the payoff-equity of the counterpart's subsequent offer.

Hypothesis 3b A negotiator's display of higher levels of other-emotions in phase three decreases the payoff-equity of the counterpart's subsequent offer.

Negotiation research has shown that dyads not reaching an agreement increase their use of contention and threats over time (Olekalns and Smith 2000). Following 
Andersson and Pearson's (1999) model, it is likely that in impasse dyads a cycle of unbalanced offers and negative affect has been triggered-they have damaged the relationship and process in the central block of the negotiation to the point that they are unable to re-introduce a constructive dynamic (Olekalns et al. 2003). Conversely, research has shown that dyads reaching an agreement do not only increase the rate of proposals towards the end of the negotiation but also make more concessions (Olekalns et al. 1996). Furthermore, in order to reach an agreement, in the resolution phase negotiators have to exchange specific substantive offers, concede on disputed issues and move closer to each other's position (Gulliver 1979). Thus, it appears that for successfully concluding the negotiation not only the joint gain is crucial but also how it is distributed among the negotiators (Vetschera and Filzmoser 2012). Consequently, we expect that efficient dyads should be characterized by further increasing the payoff-equity when moving towards a final solution during the endgame.

Hypothesis 3c In phase three, efficient settlement dyads are characterized by offers with higher payoff-equity than in phase two.

At this phase, negotiators that concluded the negotiation with an efficient outcome should also have sufficient information to be reasonably confident that an agreement is possible (Adair and Brett 2005). According to appraisal theories (Lazarus 1991), the knowledge that they are close to achieve the goals they have jointly worked for during the negotiation is likely to result in the experience of pleasure and affiliativeness (Fischer and Van Kleef 2010; Kumar 1997). Furthermore, the display of these emotions also conveys a negotiator's willingness to reach a final agreement and that the negotiation is on the right track (Barry et al. 2004; Morris and Keltner 2000). This might also serve as a counter-balance to the distributive bargaining of the endgame. Although negotiators competitively vie for a final advantage (Bednar and Curington 1983), by simultaneously displaying pleasure and other-oriented emotions they signal to the counterpart that they are confident that the negotiation will ultimately result in a mutually beneficial agreement.

Hypothesis 3d Dyads that express increased levels of pleasure from phase two to phase three are more likely to reach an agreement.

Hypothesis 3e Dyads that express increased levels of other-oriented emotions from phase two to phase three are more likely to reach an agreement.

\section{Methods}

\subsection{Data and Sample Description}

For the empirical study we analyzed dyadic, multi-attribute, mixed-motive negotiations conducted with the electronic negotiation support system (eNS) Inspire (Kersten and Noronha 1999). Subjects use Inspire to conduct a supplier-customer negotiation 
based on a case dealing with the supply of bicycle parts. The case involves a multiattribute, mixed-motive setting, allowing for both integrative and distributive strategies and outcomes. The case is neutrally framed and there is no specification as to what constitutes a good deal. Subjects are randomly matched and subsequently randomly designated as either a buyer (Cypress Cycles) or a seller (Itex Manufacturing). The participants receive a detailed explanation of the case and their role; however, no direction regarding strategy is given. Negotiators have 3 weeks' time to conclude the negotiation. Furthermore, both parties are informed that alternative buyers/sellers are available so that they can terminate the negotiation at any time without reaching an agreement.

Operational since 1995, Inspire has been used extensively for teaching and research (e.g., Hine et al. 2009; Kersten and Zhang 2003). Participants are recruited from negotiation courses for university students and practitioners. The complete negotiation process is logged by the system and stored in a database. From the 2254 logged dyadic negotiation protocols at our disposal at the time of the study we drew a random selection of 120 negotiators ( 60 dyads) with a total of 487 messages to be analyzed. The sample was balanced according to the negotiation outcome with 30 dyads concluding in a stalemate and 30 dyads reaching a close to Pareto optimal agreement according to their elicited individual utilities. This structure and size of the sample was chosen because differences between stalemate and efficient settlement dyads are of particular interest in the study. Furthermore, the multidimensional scaling (MDS) procedure that was used for evaluating the emotional content of the messages is rather demanding for the raters and larger sample sizes may result in validity and reliability problems (Malhotra et al. 1988).

We inspected the messages and the time stamps of the protocols to ensure that all selected negotiations were conducted asynchronically resembling e-mail communication rather than instant messaging. Furthermore, we included only alternating negotiations in our sample for methodological reasons (see subsequent sections). We also eliminated negotiations that included private information (e.g., the exchange of private e-mail address) as well as cases in which no agreement was reached due to time running out. Whereas the former guarantees that no communication outside of Inspire has taken place, the latter assures that the negotiators attempted to reach an agreement but 'agreed to not agree'. Negotiations not meeting these criteria were eliminated and replaced by another randomly selected negotiation. Also, the stalemate dyads in the final sample exchanged slightly more messages (8.70) than settlement dyads (7.52; $p<0.1)$. This provides further indication that they aspired to reach an agreement. The final sample consisted of 487 messages exchanged by 120 negotiators. When negotiating with Inspire, completing a pre-questionnaire is not compulsory. This limits the possibilities for sample checks and to control for demo- and psychographic variables due to the large number of missing values. We address this shortcoming empirically by employing fixed effects regressions. Fixed effects regressions introduce a dummy variable for each case in order to control for unit heterogeneity and avoid omitted variable bias (Wilson and Butler 2007). We further discuss this shortcoming in the limitations section (the data and additional analyses are available upon request). 


\subsection{Utility Elicitation and Economic Measures}

The quality of negotiation outcomes and exchanged offers is evaluated using economic criteria by means of Multi Attributive Utility Theory (MAUT) (Keeney and Raiffa 1993). By doing so, we investigate the effect of emotions on economic decisions and outcomes rather than other social-psychological measures such as perceived fairness or outcome satisfaction. Prior to the negotiation, participants were required to perform a utility evaluation as proposed by MAUT. During this process, weights and values are assigned to the issues and corresponding attributes indicating their relative importance (for a more detailed description, see, Kersten and Noronha 1999).

The so elicited utilities allow evaluating the (in)equity of each offer exchange using the contract balance and determining the negotiation outcome using Pareto efficiency. As discussed above, the contract balance is defined as the difference between the utility scores of the two negotiators and has been widely used as an economic measure of (in)equity in negotiation research (Foroughi et al. 1995). An outcome is Pareto efficient when no alternative agreement is available leaving one negotiator better off while not making the other negotiator worse off. As discussed by Tripp and Sondak (1992), Pareto efficiency has several advantages over joint profit as a measure of outcome quality. Furthermore, Tripp and Sondak (1992) point out that the impasse rate should not only be considered because it constitutes an important dependent variable in its own right but also because neglecting it could bias the other dependent variables. By comparing stalemates with Pareto efficient outcomes we investigate emotional dynamics discriminating between negotiators that have optimized joint outcome as opposed to negotiators who failed to reach an agreement.

\subsection{Emotional Content of Messages}

Whether emotions are best represented as dimensions or discrete states as well as the most appropriate taxonomy is still subject to discussion in literature (for reviews, see, Larsen and Fredrickson 1999; Mauss and Robinson 2009). Consequently, scholars suggest matching the emotional taxonomy to their particular research context (Larsen and Diener 1992) or incorporate qualitative approaches in the study of affect (Barry and Fulmer 2004). Thus, whereas hypotheses development was grounded in theory, we decided to include an inductive, data-driven element in the emotion elicitation process. A method that allows for the incorporation of an inductive, qualitative component while at the same time producing quantitative data for theory testing is multidimensional scaling (MDS). It has already been extensively used to investigate the underlying dimensions of messages, statements, or expressions in both negotiation (e.g., Griessmair and Koeszegi 2009; Pinkley et al. 2005) and emotion research (e.g., Feldman 1995; White 2000). Additionally to the general advantages of MDS (Pinkley et al. 2005), this procedure allows for capturing the emotional layer of the exchanged messages (Griessmair and Koeszegi 2009) rather than focusing on explicit emotional language or specific expressions. For alternative, discourse analytic methods to analyze the emotional layer of communication in negotiation, see Martinovsky (2015a) and Martinovsky and Mao (2009). 
MDS techniques are based on data gained by proximity judgments of the responders. To generate the proximity judgments for the present study we employed the subjective clustering method. It requires raters to sort the stimuli into homogeneous groups so that those in one group are similar to each other and dissimilar with the other groups. The 487 messages were randomly divided into two subsamples (15 successful and 15 unsuccessful negotiations each) to be sorted by two separate rater groups. Each rater received detailed instructions and performed the task independently from the others. The specific emotions were not defined a priori but the raters were free to judge the emotional similarity of the messages based on their own criteria. This enables the raters' own mental model to emerge based on their perception of the involved emotions (Pinkley et al. 2005). In a final step, the raters were asked to label or describe the underlying emotion expressed by the messages they considered as being similar. Furthermore, they marked the expression(s) in each message they used as dominant cue or trigger for assigning the specific emotion and provided an emotional rating of each group $(1=$ "very positive" to $7=$ "very negative"). The similarity matrices for the two separate groups resulting from the sorting procedures was analyzed using Proxscal.

We employed several criteria to ensure validity and reliability of results as suggested in literature (Pinkley et al. 2005). First, the negotiation protocols were randomly split into two subsamples each evaluated by a separate group of raters. The similarity judgments performed by independent rater groups on different samples should lead to equivalent results with regard to the appropriate number of dimensions and their interpretation. For determining the optimum number of dimensions describing the stimulus space, we considered goodness-of-fit, variance explanation, and interpretability as suggested by Pinkley et al. (2005). We additionally performed logistic regressions with several $n$-dimensional solutions as independent variables and the negotiation outcome as dependent variable in order to identify the number of dimensions that is suitable to explain the negotiation outcome while at the same time resulting in a parsimonious model.

For the interpretation of the dimensions we contrasted messages that load high on the opposing poles of the respective dimensions (Pinkley et al. 2005) and used the additional information collected during the sorting procedure (the emotional rating, the emotional characterization, and the marked trigger statements). The interpretation, however, was performed in light of existing emotional models to ensure that the findings are grounded in theory (cf., Adair and Brett 2005). The described procedure revealed that a 3-dimensional solution is the most appropriate in terms of interpretability, consistency with extant emotional models, and explanatory power. In both separate subsamples with a different rater group the logistic regressions point towards a 3-dimensional solution with a Nagelkerke $R^{2}$ and Stress-I of 0.37 and 0.19 and 0.40 and 0.25 , respectively. Also, the 3-dimensional solution results in consistent interpretations of the dimensions across the two subsamples and with existent dimensional models of emotions. A detailed description of the process including the logistic regressions and comparisons between the two rater groups is available from the authors. Examples of trigger statements that the raters marked as dominant emotional cue for each dimension can be found in the Table 1a-c. 


\subsubsection{Dimension 1: Pleasure-Displeasure}

Raters' characterization of the first dimension corresponds to the pleasure-displeasure dimension (Feldman 1995). Whereas messages loading high on the positive pole have been labeled 'happy', 'pleasant', 'content', or 'excited', messages on the opposite pole were described with terms such as 'angry', 'frustrated', 'cold' and 'annoyed'. Raters' emotional evaluation of the messages exhibited a consistent and highly significant correlation with the message loadings $(r=-825, p<0.001)$ providing further support. Consistent with literature (Carver and Scheier 1990; Fischer and Van Kleef 2010; Kumar 1997; Van Kleef et al. 2010), the dominant theme of trigger statements indicated by the raters and overall content of the messages reflects the rate of progress made by the negotiators and goal-congruency. Trigger statements (Table 1a) exhibiting high loadings on the displeasure pole, on the other hand, express negative emotions such as frustration, disappointment or anger as a result of not obtaining the aspired objective and unsatisfactory progress towards the desired goal, especially when the other party is held responsible (Barclay et al. 2005).

\subsubsection{Dimension 2: Solidarity-Conflict}

In contrast to pleasure, the second dimension comprises other- rather than ego-focused emotions and corresponds to what in literature is referred to as solidarity versus conflict or affiliativeness (Markus and Kitayama 1991; White 2000). This emotional dimension indicates the degree to which a person is engaged or disengaged from a personal relationship (Markus and Kitayama 1991). While not as pronounced as with the pleasure-displeasure dimension, the raters' emotional evaluation showed a consistent and highly significant correlation with the loadings $(r=-0.53, p<0.001)$. The positive pole has been described by raters as 'insightful', 'understanding', 'optimistic', or 'compromising'. Related trigger statements convey feelings of connection, respect, or familiarity and promote interdependence (Markus and Kitayama 1991). Messages on the opposite pole, on the other hand, express feelings that disrupt interdependence and were characterized by the raters as 'repellent', 'indifferent', 'hostile', or 'vengeful'. This is also conveyed in the respective trigger statements (Table 1b).

\subsubsection{Dimension 3: Submission-Dominance}

Messages loading high on the third dimension reflect the emotional dimension dominance versus submission or potency (Russell and Mehrabian 1977; White 2000). Again, emotional ratings exhibit a highly significant correlation with the message loadings ( $r=-0.45, p<0.001)$. Raters' characterizations of this dimension include 'obliging', 'considerate', and 'agreeable' as opposed to 'demanding', 'dominant', 'scornful', and 'disdainful'. Although similar to the solidarity versus conflict dimension, the focus of the third dimension is on positioning the self in relation to the other by conveying feelings that indicate the degree of control, superiority, and influence over the counterpart (Russell and Mehrabian 1977). Accordingly, trigger statements (Table 1c) with high negative loadings involve highlighting the negotiator's own qualities and position, imposing conditions, a commanding tone, and communicating one's 


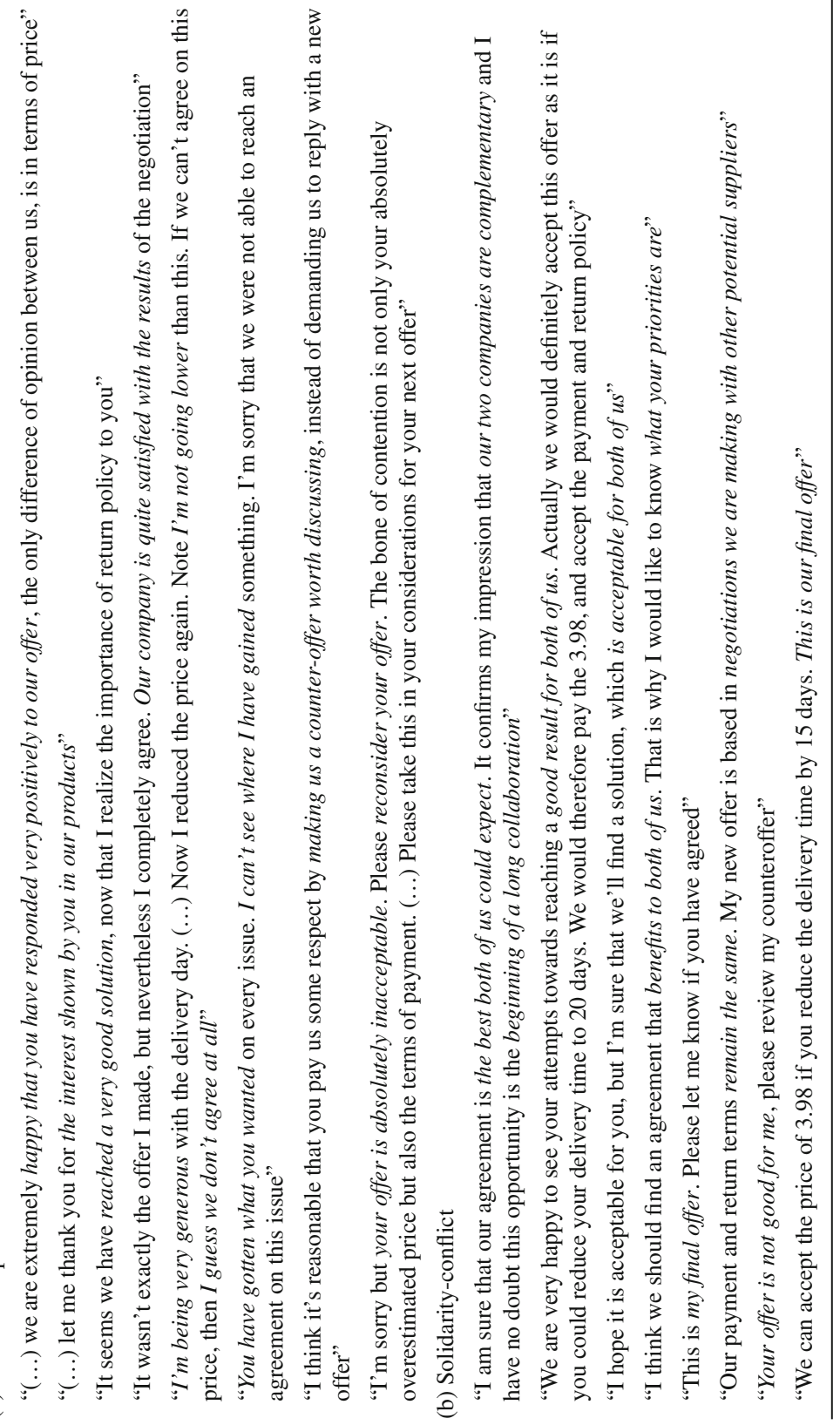




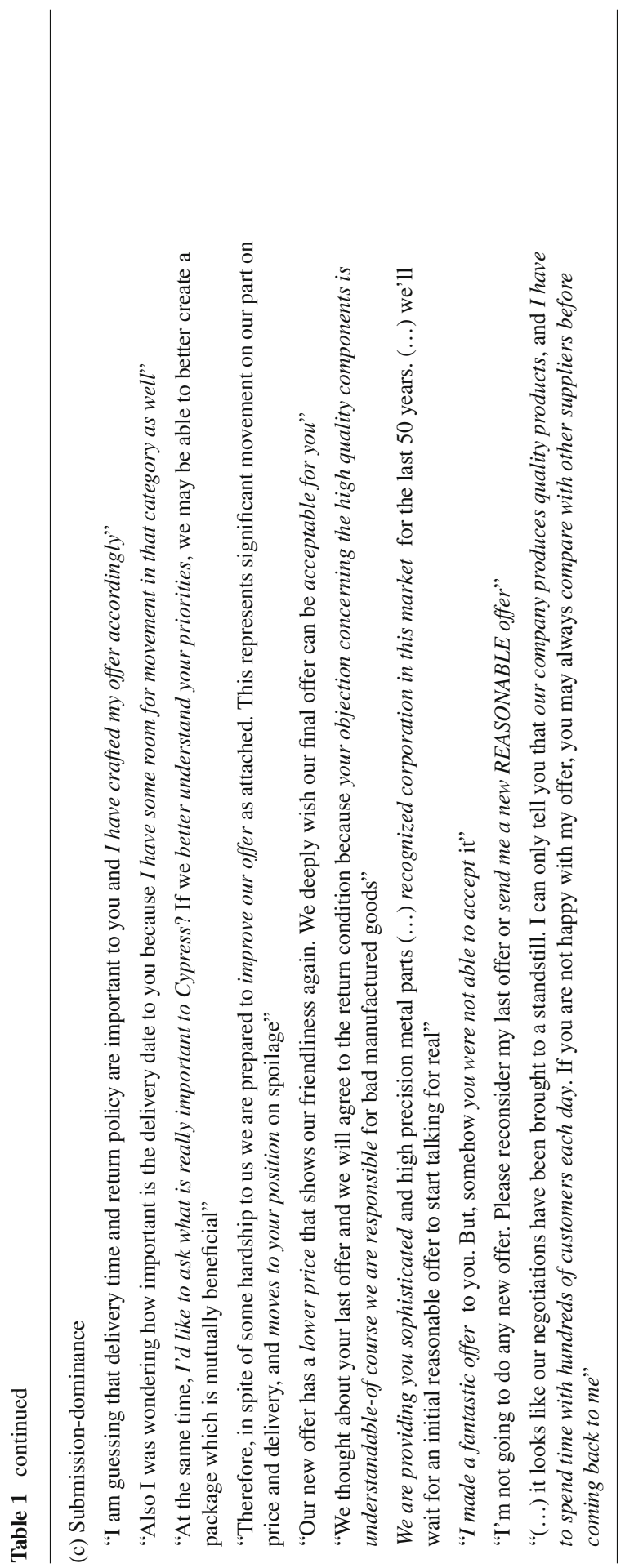


own expectations in a coercive manner. Messages on the opposing pole contain feelings of appreciation, willingness to take the other's perspective, being complaisant, and making amends for a possible transgression. Rather than highlighting one's own position, they convey signs of appeasement or emotional repair work focusing on the counterpart (Van Kleef et al. 2010).

\section{Results}

The results section is structured as follows. First, we outline the approach used for testing the hypotheses on emotional development and provide preliminary results. Second, we describe the panel regressions employed to investigate the effect of emotions on the payoff (in)equity of the counterpart's subsequent offer. Subsequently, we present the results of the hypotheses tests following the three negotiation phases-initiation, problem solving, and endgame — as described in the theory section.

\subsection{Emotional Development}

In order to determine the transitions between the phases researchers can employ the event-driven or the interval-driven approach (Adair and Brett 2005; Olekalns and Weingart 2003; Weingart et al. 2004). When using the event-driven approach the phase shifts are identified post-hoc based on content by clustering similar behavior within a dyad - a new phase begins whenever negotiators change their behavior substantially (Adair and Brett 2005; Olekalns and Weingart 2003). When using the interval-driven approach the transitions are identified a priori by dividing the negotiations into fixed time intervals (Adair and Brett 2005; Olekalns and Weingart 2003). Although the latter has been criticized as being too global to identify the progression of a given negotiation (Weingart et al. 2004), it is more suitable for testing generalizable hypotheses about differences between groups and comparable stages (Adair and Brett 2005). Since the aim of the present study is to compare effects of emotions and the emotional development between groups and across stages the interval-driven approach is more appropriate. Accordingly, the negotiations have been divided into three phases of equal length based on the number of exchanged messages. As individual phase models vary considerably in terms of number and content of phases, we decided to follow Holmes' (1992) model in which he integrates existing phase models into three phases varying according to their competitive and cooperative climate.

The three emotional dimensions as well as the contract balance were subjected to a 2 (outcome: impasse vs. efficient agreement) $\times 3$ (phases: initiation, problem solving, endgame) analysis of variance (ANOVA), with repeated measures on the latter factor. We tested for symmetry violations (Mauchly's $W$ ) and made the respective adjustments (Greenhaus-Geisser) whenever necessary in order to control for inflated $F$-statistics. With regard to the contract balance, the ANOVA revealed a significant main effect for outcome $(F=77.09, p<0.01)$ and phases $(F=9.76, p<0.01)$ as well as a significant interaction effect between outcome and phases $(F=6.89, p<0.001)$. Similarly, for the pleasure-displeasure dimension a significant main effect for outcome $(F=86.7, p<0.01)$ and phases $(F=11.74, p<0.01)$ as well as a significant 
(a)

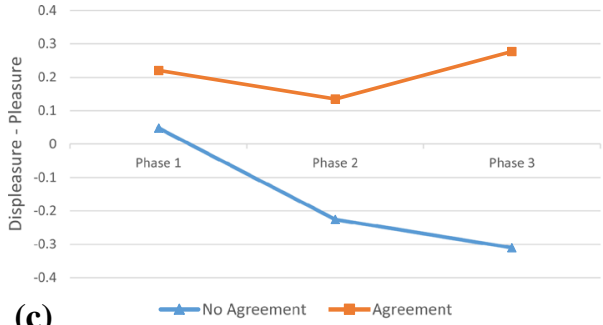

(c)

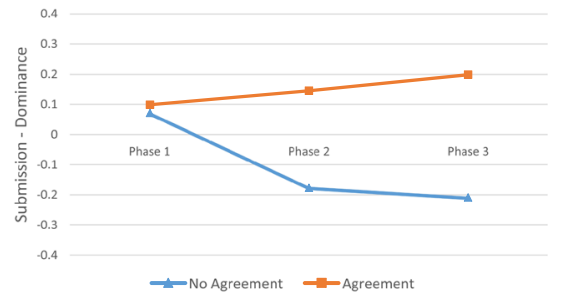

(b)
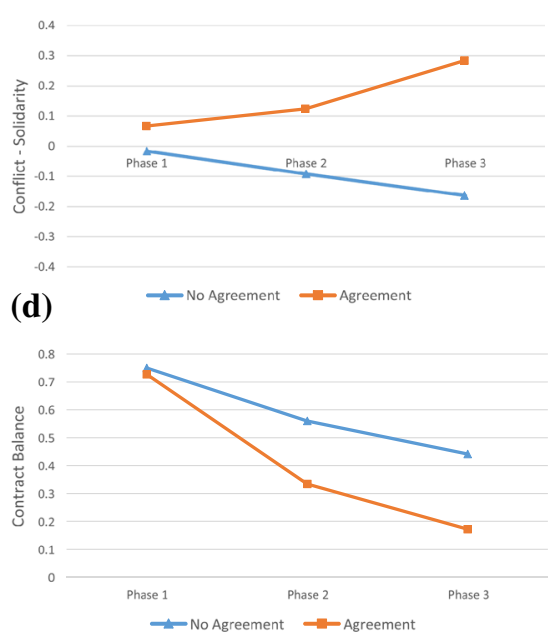

Fig. 1 Development of emotional dimensions and contract balance. a Pleasure-displeasure, b solidarityconflict, $\mathbf{c}$ submission-dominance and $\mathbf{d}$ contract balance

interaction effect $(F=13.62, p<0.01)$ was found. The main effect for phases is not significant for both solidarity-conflict $(F=0.44, p>0.1)$ and submissiondominance $(F=0.04, p>0.1)$. However, both dimensions exhibit a significant main effect for outcome (solidarity-conflict: $F=22.49, p<0.01$; submission-dominance: $F=29.07, p<0.01)$ and a significant interaction effect between outcome and phases (solidarity-conflict: $F=6.81, p<0.01$; submission-dominance: $F=6.59$, $p<0.01)$. Overall, the preliminary analyses provide strong support that efficient settlement dyads have a more positive emotional climate than stalemate dyads and that the two groups exhibit different emotional dynamics as indicated by the significant interaction effects. Figure $1 \mathrm{a}-\mathrm{d}$ plot the development over the phases of the three emotional dimensions and the contract balance. The more detailed results and tests of the proposed hypotheses on emotional development over the three phases (initiation, problem solving, and endgame) will be presented in the subsequent sections after a description of the panel regression used to investigate the effects of emotions on the payoff (in)equity of the counterpart's subsequent offer.

\subsection{Effects of Emotions on Subsequent Offer's (In)Equity}

Our data comprise observations on fixed units. Each negotiation represents a unit and the messages in chronological order with the corresponding emotional evaluation and contract balance constitute a timeline indicating the development of the negotiation. This data structure allows us to test whether the emotions expressed by a negotiator influence the contract balance of the counterpart's subsequent offer using panel regression. The contract balance of a negotiator's offer $(t)$ serves as dependent variable 
and the emotions of the counterpart's previous message $(t-1)$ are the independent variables.

To take into account the panel structure of our data we calculated fixed effects regressions with robust estimators. By including a dummy variable for each negotiation case we also control for unit heterogeneity and address the shortcoming of lacking control variables in our study (Wilson and Butler 2007). The performed Hausman tests (available from the authors upon request) also indicate that including the unit dummies is warranted. To address the serial correlation of errors we included the lagged dependent variable, contract balance in $t-1$, as independent variable (Beck and Katz 1996). By doing so, we also control for the effect the variable has on itself, considering only the additional predictive power of emotions on the (in)equity of the subsequent offer (cf., Granger 1969). It has to be noted that in fixed effects models the estimates of the lagged dependent variable can be significantly biased (Wilson and Butler 2007). This variable, however, is of no direct interest in the present study. We additionally estimated the models using the approach proposed by Beck and Katz (1996) that allows for capturing level effects and including time-invariant variables, two issues that raise concern when employing fixed effects regression (Wilson and Butler 2007). Table 2 shows the results of the fixed effects model (the results using the Beck and Katz approach are available from the authors). The results of the two approaches are largely consistent and differences regarding the variables of interest are addressed below. We performed separate regressions for each phase (models 1-3 in Table 2). We also calculated models including interaction terms between outcome and the emotional dimensions to take into account that the effects may differ between impasse and settlement dyads (models b in Table 2). The results presented in Table 2 will be discussed for each negotiation phase separately in the subsequent sections.

\subsection{Initiation}

Both, impasse and efficient settlement dyads initiate the negotiation very similarly with regard to emotional climate and the (in)equity of exchanged offers (Fig. 1a-d). Except for pleasure-displeasure, for which efficient settlement dyads exhibit a higher level $(t=-2.37, p<0.01)$, no significant differences are found in solidarity-conflict $(t=-1.10, p>0.1)$, submission-dominance $(t=-0.30 ., p>0.1)$, and contract balance $(t=0.28, p>0.1)$. Thus, the observed differences emerge primarily during the course of the interaction.

As theoretical models as well as empirical studies show that the initiation phase is characterized by a competitive and distributive climate, we hypothesized that conveying pleasure would have a negative effect on the subsequent offer's equity $(H 1 a)$. At the same time, however, negotiators have to address the "initiation problem" by conveying affiliative intent. Thus, we expected that displaying other-oriented, affiliative emotions has a positive effect $(H 1 b)$. Results confirm $H 1 a$, however, increasing solidarity has no effect and increasing submission also increases the contract balance, disconfirming hypothesis $H 1 b$ (model 1a in Table 2). When introducing interaction terms (model 1b), however, a different picture emerges. In stalemate dyads, displaying pleasure and submission to the counterparts increases the inequity of their offer. In 


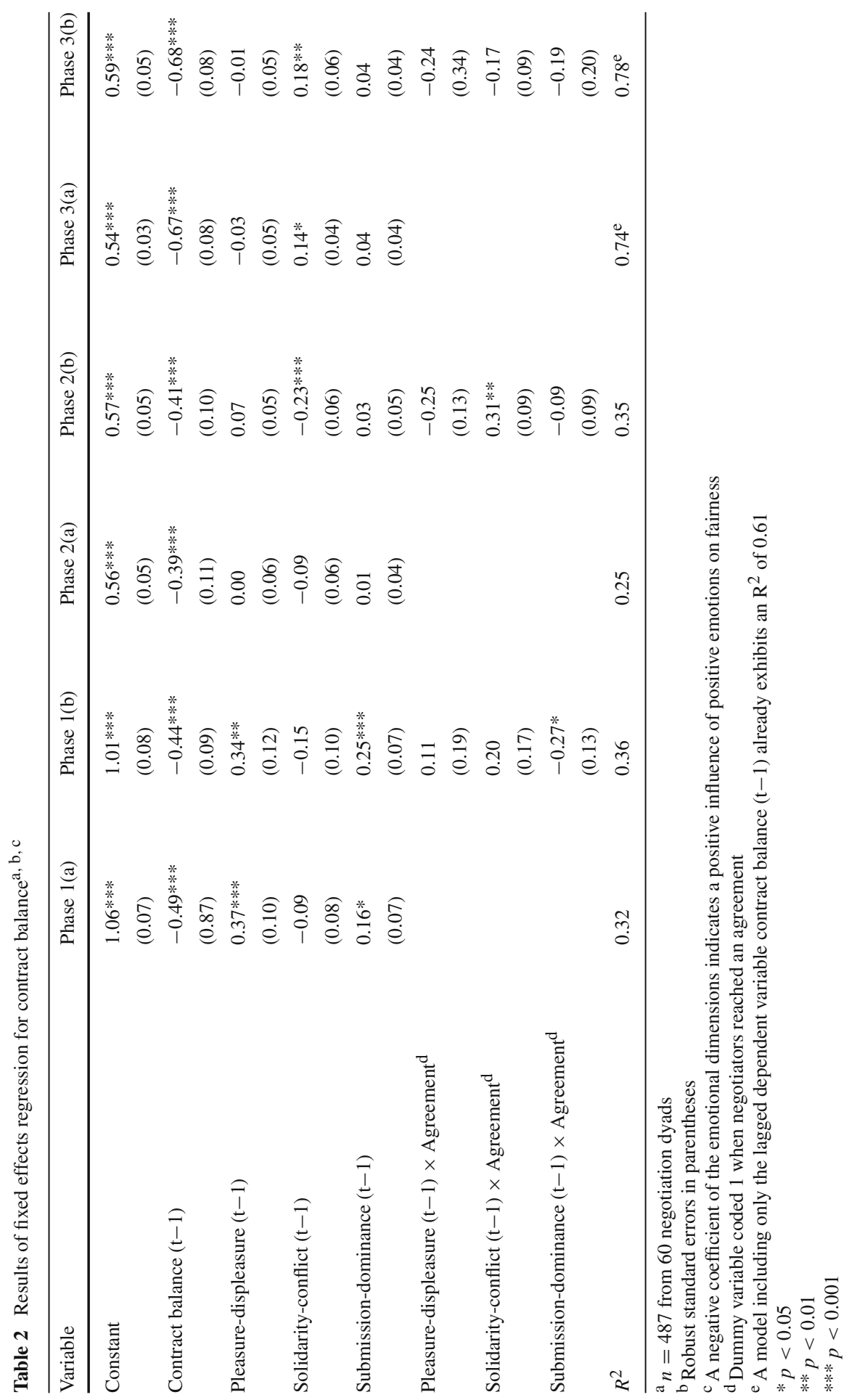


negotiations in which an efficient agreement was reached, on the other hand, making amends, being complaisant, showing signs of appeasement, and doing emotional repair work as conveyed by submission results in offers with higher equity by the counterpart. When the model is calculated with the approach proposed by Beck and Katz, the results remain consistent except for two out of the nine coefficients of interest. In the model without interaction terms (1a), dominance-submission is not significant, however, the sign of the coefficient has the same direction. In model $1 \mathrm{~b}$, the positive coefficient of solidarity-conflict for settlement negotiations becomes significant.

\subsection{Problem Solving}

We expected that in the cooperative climate of the problem solving phase higher positive levels of the emotional dimensions would result in a more equitable offer by the counterpart ( $H 2 a$ and $H 2 b$ ). None of the three emotional dimensions are significant in model $2 \mathrm{a}$ (Table 2) and the hypotheses are not supported in our analysis. In model $2 \mathrm{~b}$, when adding the interaction terms, we again find that the impact of emotions differs between efficient settlement and impasse dyads. Whereas the solidarity-conflict dimension has a negative effect in impasse dyads (increasing the offer's equity), in negotiations in which an efficient agreement was reached it has a positive effect (decreasing the offers' equity). As will be elaborated more in detail in the discussion section, the limited effect of emotions on the (in)equity of the counterpart's subsequent offer may be a result of epistemic motivation (Van Kleef et al. 2010) and equivocalness of stimuli (Kumar 1997).

Whereas we find limited support for the effects of emotions on (in)equity in the problem solving phase, the results largely confirm the proposed (in)equity and emotional dynamics. Both, efficient settlement $(t=9.12, p<0.01)$ and impasse $(t=5.52$, $p<0.01)$ dyads start making less one-sided offers compared to the initiation phase. However, the offers exchanged by efficient settlement dyads exhibit significantly higher payoff-equity $(t=3.76, p<0.01)$ (Fig. 1d). Thus, we find support for $H 2 c$ and $H 2 d$. Furthermore, the post-hoc $t$-tests show that efficient settlement dyads exhibit significantly higher levels of pleasure $(t=-7.65, p<0.01)$ and other-oriented emotions $(t=-2.95, p<0.01 ; t=-4.83, p<0.01)$. However, as predicted, efficient settlement dyads do not increase the level of positive emotions from the initiation to the problem solving phase (pleasure-displeasure: $t=1.66, p=0.11$; solidarity-conflict $t=-0.76, p>0.1$; submission-dominance: $t=-0.65, p>0.1)$. Rather, the differences result from stalemate dyads increasing displeasure $(t=4.17, p<0.01)$ and dominance $(t=2.53, p<0.05)$. While a slight increase in conflict is also observable, the increase is not significant $(t=1.24, p>0.1)$. Overall, the results confirm the emotional dynamics predicted in $H 2 e$ to $H 2 h$ (Fig. $1 \mathrm{a}-\mathrm{d}$ ).

\subsection{Endgame}

In the endgame, negotiators focus on exchanging offers and counteroffers and turn again toward being more competitive. Thus, we expected that higher positive levels of the emotional dimensions would result in more one-sided offers ( $H 3 a$ and $H 3 b$ ). 
Whereas solidarity-conflict significantly increases the inequity of the subsequent offer by the counterpart as expected, submission-dominance and pleasure-displeasure are not significant (Table 2). When the model is calculated using the approach proposed by Beck and Katz, pleasure-displeasure becomes significant with a positive coefficient as hypothesized. In model $2 \mathrm{~b}$ containing the interaction terms, solidarity-conflict still significantly increases the inequity in stalemate dyads, but not for negotiation dyads reaching an efficient agreement. In settlement negotiations, the sign of the coefficient indicates that higher levels of solidarity decrease the inequity of the subsequent offer, however, it is only significant at the $10 \%$-level in the fixed effects model and not significant when using the Beck and Katz approach.

Similar to the problem solving phase, the effects of emotions on (in)equity in the endgame are not as pronounced as in the initiation phase. However, the results largely confirm the proposed (in)equity and emotional dynamics. As predicted $(H 3 c$ and $H 3 d)$, efficient settlement dyads increase the equity of exchanged offers ( $t x=5.52$, $p<0.01)$ and pleasure $(t=3.66, p<0.01)$. They do not, however, substantially increase other-oriented emotions $(\mathrm{H} 3 e)$. Compared to phase two, the change of the submission-dominance dimension is not significant $(t=-0.87, p>0.1)$ and the increase in solidarity is only significant at the $10 \%$-level $(t=-2.03, p<0.1)$. For stalemate dyads, an increase in displeasure at the $10 \%$-level $(t=1.79, p<0.1)$ and no significant increase in dominance $(t=0.47, p>0.1)$ and conflict $(t=1.33$, $p>0.1)$ is observable. Thus, they carry over the negative climate of the problem solving phase to the endgame. Stalemate dyads increase the equity of exchanged offers in the endgame $(t=3.73, p<0.01)$, however, the equity level is still significantly lower than in efficient settlement dyads $(t=4.23, p<0.01)$ and apparently not sufficient for reaching a mutually satisfactory agreement.

\section{Discussion}

This study investigated emotional development in negotiations and its effect on (in)equity. It extends prior knowledge by showing how emotions evolve during the course of the negotiation and how the display of specific emotions affects the degree of (in)equity of the counterpart's subsequent offer. By comparing efficient settlement with stalemate dyads, the study identifies the emotional dynamics differentiating between an impasse as opposed to an efficient outcome. It further shows that emotions are not only reactions to events that are perceived as (un)fair, but their display also influences the payoff-(in)equity of subsequent offers. The results contribute to negotiation theory, in particular phase models, the social-functional effects of emotions, and shed light on the emergence of conflict spirals.

Prior research linking emotions to negotiation outcomes has treated emotions as a static rather than as a dynamic phenomenon. Consistent with these studies, our study also finds that overall settlement negotiations are emotionally more positive than stalemate negotiations; however, it provides a more detailed picture. Based on phase model and emotion theory, we find that the observed differences are primarily the result of impasse dyads spiraling into a negative emotional climate rather than efficient settlement dyads having overall higher levels of positive emotions or increasing them 
throughout the negotiation process. Furthermore, displaying higher rather than lower levels of positive emotions may also increase the inequity of the subsequent offer.

Both groups begin the negotiation with one-sided offers exhibiting the same high contract balance. Thus, starting with rather unbalanced offers and counteroffers in order to stake a claim and establish an anchor does not appear to be detrimental to reaching an agreement. However, increasing the level of the offers' equity at a faster pace, as efficient settlement compared to stalemate dyads did, seems crucial for reaching an agreement.

Additionally, negotiators reaching an efficient outcome pair the initial one-sided offers with higher levels of pleasure. The first phase is influential in shaping the overall tone of the negotiation (Friedman et al. 2004; Olekalns et al. 2003) and emotions have a significant priming effect when individuals are faced with complex tasks (Forgas 1998). Displaying positive, goal-oriented emotions at the beginning of the negotiation conveys a positive outlook and frames the remainder of the negotiation. Perhaps even more importantly, in efficient settlement dyads displaying higher rather than lower levels of pleasure does not increase the inequity of the counterpart's subsequent offer as it is the case for impasse dyads.

When entering the cooperative second phase, efficient settlement dyads neither significantly increase pleasure nor other-oriented emotions but rather keep the emotional level established in the first phase. Shifting from the competitive first phase to the more cooperative second phase would intuitively be associated with an increase of positive emotions. Yet, this might result in a relational satisficing dynamic (Gelfand et al. 2006) deterring negotiators from reaching an efficient agreement. This is also consistent with research on negotiation strategies showing that optimum outcomes are characterized by some level of contentiousness and the usage of distributive strategies in the middle of the negotiation (Olekalns et al. 1996). Efficient settlement dyads, however, increase pleasure, and to some extent other-oriented emotions, in the third phase. The positive emotional climate may serve as a counterbalance to the competitive endgame tactics, signaling that both negotiators are confident that a mutually beneficial agreement will ultimately be reached. Again, displaying higher rather than lower levels of positive emotions, specifically solidarity-conflict, does not increase the inequity of the subsequent offer as is the case for impasse dyads.

Impasse dyads exhibit a pronounced emotional decline when moving from the first to the second phase. Although they start with the same level of other-oriented emotions as settlement dyads, they strongly increase displeasure and dominance. This might have damaged the process and relationship to the point that a constructive dynamic cannot be re-introduced. In fact, the negative emotional climate from the second phase is carried over to the third phase. The rise of feelings of dominance might be especially crucial as they are associated with attacking face (Brett et al. 2007). Attacking the counterpart's face by conveying feelings of dominance in the second phase, in which negotiators are supposed to create value, is most likely a major stumbling block for reaching an agreement.

The observed effects of emotions on the (in)equity of the counterpart's subsequent offer and the emotional development might also provide a novel view of the emergence of conflict spirals. Conflict cycles are characterized by the continuous reciprocation of contentious communications and negative affect (Brett et al. 1998). Our results 
shed some light on what gives rise to the spiral in the first place. Efficient settlement and impasse dyads start with the same level of other-oriented emotions, yet their impact on subsequent offers differs substantially. Negotiators in dyads reaching an efficient agreement interpret higher rather than lower levels of submission compared to dominance as a signal to come closer and subsequently make offers with a higher payoff-equity. Conversely, in impasse dyads displaying higher rather than lower levels of submission and pleasure invites exploitation. This initial interaction is influential for the further progress of the negotiation because it sends signals about the strategic orientation and provides a stimulus for reciprocity (Olekalns and Weingart 2003). Negotiators in efficient settlement dyads have learned that emotional signals of moving towards are reciprocated by the counterpart with more equitable counteroffers, which builds trust and aids in establishing the necessary climate for creating value in the middle of the negotiation. In impasse dyads, on the other hand, the exploitation of positive emotions might trigger the conflict spiral. Having experienced that emotional signals of moving toward result in more one-sided offers proposed by the counterpart, they are not likely to show these emotions again and react with displeasure and dominance. When reciprocated, the negotiators lock into a negative affect cycle (Brett et al. 1998). Notably, the emotional dimensions that increase the inequity of the counteroffer for impasse dyads in the first phase are also the ones that strongly decrease in the second phase. The negative climate of the second phase is then carried over to the third round, ultimately resulting in an impasse.

Overall, we find strong support for the proposed emotional dynamics in our study. The results regarding the effects of emotions on the (in)equity of the subsequent offer, however, are mixed. Thus, two additional issues not addressed in our model require further consideration. First, the empirical results indicate that the impact of emotions is strongest in the first phase and decreases considerably over time. Beside the fact that the initiation phase has a stronger focus on relation and emotions than the other two (Adair and Brett 2005), a consistent finding in emotion research is that the impact of emotions is strongest when epistemic motivation is high (Van Kleef et al. 2010) and stimuli are equivocal (Kumar 1997). In the initiation phase, negotiators have little information about the counterpart (Adair and Brett 2005). Thus, the motivation to process information about the counterpart's needs and interests as well as the ambiguity of his or her behavior is higher than in the subsequent phases. In such a situation emotions play a more dominant role in interpreting and reacting to the counterpart's behavior. Over the course of the negotiation, the parties become more familiar with and gain more information about each other. Consequently, epistemic motivation and ambiguity decrease, potentially resulting in the diminished impact of emotions in the second and third phase as observed in our study.

Second, and possibly more importantly, the impact emotions have on the (in)equity of the counterpart's subsequent offer differs between stalemate and efficient settlement dyads. In developing our hypotheses, we considered the context in terms of negotiation phases, however, as pointed out by Olekalns and Weingart (2003: 21), "although the negotiation context is known at the outset, the other party's interpretation and enactment of that context are not." In fact, we already find differences between settlement and impasse dyads in the first phase, suggesting that differences at the individual or dyad level may play an important role. Van Kleef et al. (2010) propose that the effects 
of emotions depend on whether the negotiation climate is cooperative or competitive, yet, research shows that negotiators are also strongly influenced by their strategic orientation (Olekalns et al. 1996), their relational goals (Olekalns and Weingart 2003), and their conflict frames (Pinkley and Northcraft 1994). Thus, whether negotiators exploit positive emotions or take them as a sign to come closer may also, for instance, depend on whether they hold a distributive versus an integrative strategic orientation or their conflict frame is "win" rather than "cooperate". Whereas the context is without any doubt a major factor in determining reactions to emotional expressions as proposed by Van Kleef et al. (2010), individual characteristics of the negotiator may moderate this relationship by influencing how the context is interpreted.

\subsection{Strengths, Limitations, and Opportunities for Further Research}

A major question regarding our results is the extent to which the findings can be generalized to face-to-face negotiations, group negotiations or other negotiation contexts. There is ample evidence of the effect of emotions in a broad array of social interactions similar to our study, also including mediating variables such as power, appropriateness, vulnerability, and motivation to consider information (Friedman et al. 2004; Sinaceur and Tiedens 2006). The extent to which the specific results obtained in this study are influenced by the negotiation context opens avenues for future research. For instance, in our study we focused on dyadic negotiations and did not consider negotiations within or between groups. Research shows that emotions also play an important role in group interactions (Barsade and Gibson 1998; Kelly and Barsade 2001; Martinovsky 2015a), however, only limited research addresses their effects in a group negotiation setting. Additionally, group-level emotions may have a distinctive influence on the course of the negotiation. Group-level emotions are a distinct phenomenon and result from a group's affective composition and its affective context (Kelly and Barsade 2001). Investigating how group-level and individual emotions interact and how they shape the negotiation process and outcome are an interesting venue for future research.

Furthermore, compared to face-to-face negotiations, our computer mediated negotiations are characterized by weaker social presence, slower turn-taking with longer messages, and the lack of para-verbal communication as major carrier for conveying emotions (Friedman and Currall 2003). These and other features may have exacerbated the conflict that we observed in the impasse negotiations (Friedman and Currall 2003). However, a number of scholars also argue that asynchronous computer mediated communication inhibits conflict escalation and promotes rational, task-oriented behavior in negotiations as the parties have more time to calm down and reflect upon their arguments as well as to evaluate the consequences of their (affective) behavior (Foroughi 1998). Similarly, the nature of the relationship-for instance familiarity of the individuals, their relational history, or the distribution of power between the parties-might influence the display of emotions and their effects on the counterpart (Friedman and Currall 2003). These and other factors limit the generalizability of our results, but also provide interesting areas for future research. 
A limitation of our study is the lack of additional explanatory variables potentially influencing our results. By employing a fixed effects model we controlled for omitted variable bias (Wilson and Butler 2007), however, this does not allow drawing any meaningful theoretical conclusions. Our hypotheses were motivated by phase model theory and social-functional models of emotion but did not consider individual differences. Individual differences, however, may play an important moderating role in determining reactions to emotional displays. On one hand, individual characteristics of negotiators such as their strategic orientation (Olekalns et al. 1996), their relational goals (Olekalns and Weingart 2003), or how the encounter is framed (Pinkley and Northcraft 1994) may influence how the context is interpreted. On the other hand, factors such as emotional intelligence or differences in mindful and strategic emotion management may influence the extent to which and how emotional displays by the counterpart are perceived and processed. Investigating how these individual differences affect reactions to emotional expressions may provide additional insights into the working mechanisms of emotions in social interactions.

A further issue that merits discussion is the type of emotions employed in our study. The lack of consistent definitions of emotions is a general problem in emotion research and the majority of studies in the realm of negotiation focus on general positive and negative affect (Barry et al. 2004). Our study goes beyond that by employing dimensions derived from the social functional approach and including an inductive component in order to match the investigated emotions to the research context as advocated by Larsen and Diener (1992). Although emotional dimensions capture the lion's share of variance and are considered more appropriate-or at least sufficientby a number of researchers (Mauss and Robinson 2009), other scholars provide a compelling theoretical rationale for differentiating between discrete emotional states (Morris and Keltner 2000; Van Kleef et al. 2010). The discussion as to whether emotions are best conceptualized as general dimensions or distinct categories goes back to Darwin and continues to this day (Larsen and Fredrickson 1999) and a definitive answer is beyond the scope of this study. The present study provides first evidence for the development and effect of emotional dimensions over time; however, investigating specific, discrete emotions in a similar setting may provide a more detailed, fine-grained picture. Similarly, integrating more complex, hybrid conceptualizations of emotions into negotiation research such as the evaluation space model (Cacioppo and Berntson 1994), or prototypical emotional episodes (Russell and Feldman Barrett 1999) may open promising areas of future research.

Open Access This article is distributed under the terms of the Creative Commons Attribution 4.0 International License (http://creativecommons.org/licenses/by/4.0/), which permits unrestricted use, distribution, and reproduction in any medium, provided you give appropriate credit to the original author(s) and the source, provide a link to the Creative Commons license, and indicate if changes were made.

\section{References}

Adair WL, Brett JM (2005) The negotiation dance: time, culture, and behavioral sequences in negotiation. Organ Sci 16:33-51 
Anderson C, Thompson LL (2004) Affect from the top down: how powerful individuals' positive affect shapes negotiations. Organ Behav Hum Decis Process 95:125-139

Andersson LM, Pearson CM (1999) Tit for tat? The spiraling effect of incivility in the workplace. Acad Manag Rev 24:452-471

Barclay LJ, Skarlicki DP, Pugh SD (2005) Exploring the role of emotions in injustice perceptions and retaliation. J Appl Psychol 90:629-643

Barry B, Fulmer IS (2004) Methodological challenges in the study of negotiator affect. Int Negot 9:485-502

Barry B, Fulmer IS, Van Kleef GA (2004) I laughed, I cried, I settled: The role of emotion in negotiation. In: Gelfand M, Brett JM (eds) The handbook of negotiation and culture. Stanford University Press, Stanford, pp 71-94

Barsade SG, Gibson DE (1998) Group emotion: a view from top and bottom. In: Gruenfeld D, Mannix B, Neale M (eds) Research on managing on groups and teams. JAI Press, Stamford, pp 81-102

Barsade SG, Gibson DE (2007) Why does affect matter in organizations? Acad Manage Perspect 21:36-59

Beck N, Katz JN (1996) Nuisance vs. substance: specifying and estimating time-series-cross-section models. Polit Anal 6:1-36

Bednar DA, Curington WP (1983) Interaction analysis: a tool for understanding negotiations. Ind Labor Relat Rev 36:389-401

Brett JM, Olekalns M, Friedman RA, Goates N, Anderson C, Lisco CC (2007) Sticks and stones: language, face, and on-line dispute resolution. Acad Manag J 50:85-99

Brett JM, Shapiro DL, Lytle AL (1998) Breaking the bonds of reciprocity in negotiations. Acad Manag J 41:410-424

Brief AP, Weiss HM (2002) Organizational behavior: affect in the workplace. Annu Rev Psychol 53:279-307

Cacioppo JT, Berntson GG (1994) Relationship between attitudes and evaluative space: a critical review with emphasis on the separability of positive and negative substrates. Psychol Bull 115:401-423

Carver CS, Scheier MF (1990) Origins and functions of positive and negative affect: a control process view. Psychol Rev 97:19-35

Cropanzano R, Stein JH, Nadisic T (2011) Social justice and the experience of emotion. Taylor and Francis Group, New York

Druckman D, Olekalns M (2008) Emotions in negotiation. Group Decis Negot 17:1-11

Druckman D, Olekalns M (2015) With feeling: how emotions shape negotiation. In: Martinovsky B (ed) Emotion in group decision and negotiation. Springer, Dordrecht, pp 33-50

Feldman L (1995) Valence focus and arousal focus: Individual differences in the structure of affective experience. J Pers Soc Psychol 69:153-166

Fischer AH, Van Kleef GA (2010) Where have all the people gone? A plea for including social interaction in emotion research. Emot Rev 2:208-211

Forgas JP (1998) On feeling good and getting your way: mood effects on negotiator cognition and bargaining strategies. J Pers Soc Psychol 74:565-577

Foroughi A (1998) Minimizing negotiation process losses with computerized negotiation support systems. J Appl Bus Res 14:15-26

Foroughi A, Perkins WC, Jelassi MT (1995) An empirical study of an interactive, session-oriented computerized negotiation support system (NSS). Group Decis Negot 4:485-512

Friedman RA, Anderson C, Brett JM, Olekalns M, Goates N, Lisco CC (2004) The positive and negative effects of anger on dispute resolution: evidence from electronically mediated disputes. J Appl Psychol 89:369-376

Friedman RA, Currall SC (2003) Conflict escalation: dispute exacerbating elements of e-mail communication. Hum Relat 56:1325-1347

Gelfand MJ, Smith Major V, Raver JL, Nishii L, O’Brien K (2006) Negotiating relationally: the dynamics of the relational self in negotiations. Acad Manag Rev 31:427-451

Gibson FP, Fichman M (2006) Emotions as information in bargaining: what happens when the credit collector calls? Emotion 20:1108-1131

Granger CWJ (1969) Investigating causal relations by econometric models and cross-spectral methods. Econometrica 37:424-438

Griessmair M, Hippmann P, Gettinger J (2015) Emotions in e-negotiations. In: Martinovsky B (ed) Emotion in group decision and negotiation. Springer, Dordrecht, pp 101-135

Griessmair M, Koeszegi ST (2009) Exploring the cognitive-emotional fugue in electronic negotiations. Group Decis Negot 18:213-234

Gulliver PH (1979) Disputes and negotiations: a cross-cultural perspective. Academic Press, New York 
Hegtvedt KA, Killian C (1999) Fairness and emotions: reactions to process and outcomes of negotiations. Soc Forces 78:269-303

Hine MJ, Murphy SA, Weber W, Kersten G (2009) The role of emotion and language in dyadic enegotiations. Group Decis Negot 18:193-211

Holmes ME (1992) Phase structures in negotiations. In: Putnam LL, Roloff ME (eds) Communication and negotiation. Sage, Newbury Park, pp 83-105

Keeney RL, Raiffa H (1993) Decisions with multiple objectives: preferences and value tradeoffs. Cambridge University Press, New York

Kelly JR, Barsade SG (2001) Mood and emotions in small groups and work teams. Organ Behav Hum Decis Process 86:99-130

Kersten GE, Noronha SJ (1999) WWW-based negotiation support: design, implementation, and use. Decis Support Syst 25:135-154

Kersten GE, Zhang G (2003) Mining inspire data for determinants of successful internet negotiations. CEJOR 11:297-316

Kumar R (1997) The role of affect in negotiations: an integrative overview. J Appl Behav Sci 33:84-100

Larsen RJ, Diener E (1992) Promises and problems with the circumplex model of emotion. In: Clark MS (ed) Emotion: review of personality and social psychology. Sage, Thousand Oaks, pp 25-59

Larsen RJ, Fredrickson BL (1999) Measurement issues in emotion research. In: Kahneman D, Diener E, Schwarz N (eds) Well-being: foundations of hedonic psychology. Sage, New York, pp 40-60

Lazarus RS (1991) Emotion and adaptation. Oxford University Press, New York

Lazarus RJ, Saunders DM, Minton JW (1999) Negotiation, 3rd edn. McGraw-Hill, Boston

Lewicki RJ, Saunders DM, Minton JW (1999) Negotiation, 3rd edn. McGraw-Hill, Boston

Lytle AL, Brett JM, Shapiro DL (1999) The strategic use of interests, rights, and power to resolve disputes. Negot J 15:31-51

Malhotra NK, Jain AK, Pinson C (1988) The robustness of MDS configurations in the case of incomplete data. J Mark Res 25:95-102

Markus HR, Kitayama S (1991) Culture and the self: implications for cognition, emotion, and motivation. Psychol Rev 98:224-253

Martinovsky B (2015a) Discourse analysis of emotion in face-to-face group decision and negotiation. In: Martinovsky B (ed) Emotion in group decision and negotiation. Springer, Dordrecht, pp 137-188

Martinovsky B (ed) (2015b) Emotion in group decision and negotiation. Advances in group decision and negotiation. Springer, Dordrecht

Martinovsky B, Mao W (2009) Emotion as an argumentation engine: modeling the role of emotion in negotiation. Group Decis Negot 18:235-259

Martinovsky B, Traum D, Marsella S (2007) Rejection of empathy in negotiation. Group Decis Negot 16:61-76

Mauss IB, Robinson MD (2009) Measures of emotion: a review. Cogn Emot 23:209-237

Morris W, Keltner D (2000) How emotions work: the social functions of emotional expression in negotiations. Res Organ Behav 22:1-50

O'Conner KM, Arnold JA (2001) Distributive spirals: negotiation impasses and the moderating role of disputant self-efficacy. Organ Behav Hum Decis Process 84:148-176

Olekalns M, Brett JM, Weingart LR (2003) Phases, transitions and interruptions: modeling processes in multi-party negotiations. Int J Confl Manag 14:191-211

Olekalns M, Smith PL (2000) Understanding optimal outcomes: the role of strategy sequences in competitive negotiations. Hum Commun Res 26:527-557

Olekalns M, Smith PL, Walsh T (1996) The process of negotiating: strategy and timing as predictors of outcomes. Organ Behav Hum Decis Process 68:68-77

Olekalns M, Weingart L (2003) Think globally, act locally: towards an adaptive model of dyadic negotiations in organizations. In: Paper presented at the 16th annual conference of the international association for conflict management, Melbourne, Australia

Osgood CE (1969) On the whys and wherefores of E, P, and A. J Pers Soc Psychol 12:194-199

Pinkley RL, Gelfand MJ, Duan L (2005) When, where, and how: the use of multidimensional scaling methods in the study of negotiation and social conflict. Int Negot 10:79-96

Pinkley RL, Northcraft GB (1994) Conflict frames of reference: implications for dispute processes and outcomes. Acad Manag J 37:193-205

Russell JA, Feldman Barrett L (1999) Core affect, prototypical emotional episodes, and other things called emotion: Dissecting the elephant. J Pers Soc Psychol 76:805-819 
Russell JA, Mehrabian A (1977) Evidence for a three-factor theory of emotions. J Res Pers 11:273-294

Sinaceur M, Tiedens LZ (2006) Get mad and get more than even: when and why anger expression is effective in negotiations. J Exp Soc Psychol 42:314-322

Tripp TM, Sondak H (1992) An evaluation of dependent variables in experimental negotiation studies: impasse rates and pareto efficiency. Organ Behav Hum Decis Process 51:273-295

Van Kleef GA, De Dreu CKW, Manstead ASR (2004) The interpersonal effects of anger and happiness in negotiations. J Pers Soc Psychol 86:57-76

Van Kleef GA, De Dreu CKW, Manstead ASR (2010) An interpersonal approach to emotion in social decision making: the emotions as social information model. Adv Exp Soc Psychol 42:45-96

Vetschera R, Filzmoser M (2012) Standardized interpolated path analysis of offer processes in enegotiations. In: ICEC ' 12 proceedings of the 14th annual international conference on electronic commerce, pp 134-140

Watson D, Wiese D, Vaidya J, Tellegen A (1999) The two general activation systems of affect: structural findings, evolutionary considerations, and psychobiological evidence. J Pers Soc Psychol 76:820-838

Weingart LR, Olekalns M, Smith PL (2004) Quantitative coding of negotiation behavior. Int Negot 9:441455

White GM (2000) Representing emotional meaning: category, metaphor, schema, discourse. In: Lewis M, Haviland-Jones JM (eds) Handbook of emotions. Guilford Press, New York, pp 30-44

Wilson SE, Butler DE (2007) A lot more to do: the sensitivity of time-series cross-section analyses to simple alternative specifications. Polit Anal 15:101-123 